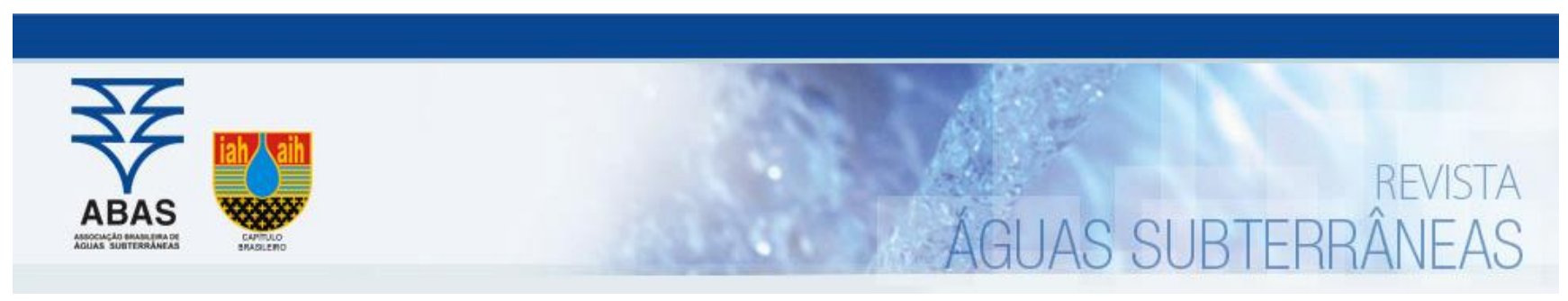

Artigos

\title{
Uso de imagens do projeto PE3D para nivelamento de poços a serem usados em confecção de mapas potenciométricos
}

\author{
Use of imagens from the PE3D project for leveling wells to be used in \\ making potentiometric maps
}

\author{
Gisely Maria Silva1; José Geilson Alves Demetrio ${ }^{1 凶}$ \\ 1 Universidade Federal de Pernambuco (UFPE), Recife, PE \\ giselymaria.silva@gmail.com,geilsonad@yahoo.com.br
}

Palavras-chave:

Mapa potenciométrico.

DGPS.

PE3D.

Nivelamento.
Resumo

Para confecção de mapas potenciométricos é necessário dispor das cotas do terreno a fim de obter o valor das cargas hidráulicas, porém, a obtenção dessas cotas por meio de levantamentos topográficos nem sempre é tão rápida e fácil. 0 uso de imagens de satélite para esse fim é frequente. 0 objetivo desse trabalho é avaliar a efetividade do uso de imagens do projeto Pernambuco Tridimensional (PE3D) para construção de mapas potenciométricos. 0 projeto PE3D trata-se de um recobrimento aerofotogramétrico de todo o estado de Pernambuco com alta precisão. Para atestar esse propósito foram feitos levantamentos topográficos utilizando o Differential Global Positioning System (DGPS), que fornece precisão até milimétrica. Esses levantamentos foram feitos em duas áreas diferentes, uma delas localizada na Bacia Sedimentar de Carnaubeira da Penha (PE) e outra na Bacia Sedimentar de Cedro (PE), somando 32 pontos. A partir desse levantamento as maiores diferencas entre as cotas obtidas por meio do DGPS e as cotas obtidas pelas imagens do PE3D, em termos absolutos, foi de $0,625 \mathrm{~m}$, enquanto a menor diferença foi $0,007 \mathrm{~m}$, sendo então a média $0,211 \mathrm{~m}$. Também foram comparados os resultados do GPS de navegação, pois as coordenadas $(X, Y)$ utilizadas no caso anterior foram adquiridas pelo DGPS, e este não é utilizado nos trabalhos de campo habituais. A maior diferença entre as coordenadas obtidas pelo GPS comum e o DGPS foi de 4,724 m, enquanto a menor diferença foi de 0,246 m, sendo então a média $1,780 \mathrm{~m}$. Essas diferenças, portanto, não são suficientes para que a cota obtida pelo GPS comum apresente erros que mudem a forma do mapa potenciométrico. Conclui-se também que o uso de imagens do projeto PE3D é recomendado para estudos tanto de caráter regional, quanto para estudos detalhados.

DGPS.

PE3D.

Leveling.

Revisado por pares.

Recebido em: 13/05/2019.

Aprovado em: 13/04/2020.

\begin{abstract}
The satellite images are often used to obtain terrain quotes, which contribute to the production of potentiometric maps since traditional topographic survey takes time and are expensive. The aim of this paper is to evaluate the effectiveness of the imaging from the Pernambuco Tridimensional project (PE3D) focusing on generating potentiometric maps. The PE3D project consists of a high precision airborne cover from the Pernambuco State. In order to attest this purpose, topographic surveys were carried out using the Differential Global Positional System (DGPS), which provide millimetric precision. Such surveys were performed in two distinct areas giving in 32 points. The results showed that the major differences between the quote obtained by DGPS and the PE3D images, in absolute terms, were $0.625 \mathrm{~m}$ whereas the minor difference was $0.007 \mathrm{~m}$ with an average of $0.211 \mathrm{~m}$. Navigation GPS results were also compared and the principal difference between the navigation GPS coordinates and the DGPS was $4.724 \mathrm{~m}$ while the smallest difference was 0.246 $\mathrm{m}$ with an average of $1.780 \mathrm{~m}$. These differences were not enough to show that the quote obtained by GPS displayed errors in the shapes of the potentiometric maps. It is also concluded that imaging from the PE3D project is recommended for regional and detailed studies.
\end{abstract}

DOI: http:/dx.doi.org/10.14295/ras.v34i1.29551

\section{INTRODUÇÃO}

O nivelamento topográfico consiste em uma etapa importante para confecção de mapas potenciométricos, uma vez que nos fornece a cota do terreno necessária para o cálculo das cargas hidráulicas. Existem diferentes formas de obter os dados de cota, porém uma das mais usadas atualmente é o DGPS (Differential Global Positioning System), que fornece precisão na faixa de milímetros. Entretanto, esta técnica mais elaborada requer trabalho de campo, equipamentos de alto custo e pessoas especializadas. Estudos anteriores comparando a utilização de imagens SRTM (Shuttle Radar Topography Mission) com o DGPS mostraram que os erros na obtenção das cotas são inferiores a 5 metros (Demetrio et. al, 2006). Löbler et. al (2014) utiliza dados de SRTM comparados ao banco de dados do Sistema de Informações de Águas Subterrâneas (SIAGAS/CPRM) e após aplicado o Coeficiente de Correlação por Postos de Spearman, obteve-se o valor 0,887 para um nível 
de significância de 99\%. Isso indica que os valores foram próximos de 1, concluindo que as imagens SRTM podem servir de instrumento em estudos nas áreas em que há carência de informações. Para o estado de Pernambuco, uma opção acessível atualmente é a obtenção da cota do terreno por meio do Programa Pernambuco Tridimensional (PE3D), que encontrase disponível gratuitamente na plataforma www.pe3d.pe.gov.br. Esse projeto consiste em um recobrimento aerofotogramétrico de todo território pernambucano e geração de ortofotos na escala de 1:5.000, perfilamento a laser com precisão altimétrica melhor que $25 \mathrm{~cm}$ e geração de Modelos Digitais de Terreno (MDT), Modelos Digitais de Elevação (MDE) e imagens de Intensidade Hipsométrica. 0 presente trabalho tem como objetivo a obtenção das cotas de um conjunto de poços nas bacias sedimentares de Cedro e Carnaubeira da Penha, por meio do DGPS e das imagens do PE3D, a fim de analisar a possibilidade do uso das imagens do PE3D para a elaboração de mapas potenciométricos, reduzindo as- sim os custos e o tempo necessário para obtenção das cotas do terreno com precisão satisfatória.

\section{2. ÁREA DE ESTUDO}

A área de estudo encontra-se no âmbito das bacias interiores de Pernambuco, estando localizadas nas Bacias sedimentares de Cedro e Carnaubeira da Penha (Figura 1). Geologicamente, estão inseridas na Província Borborema, na Subprovíncia Central ou Zona Transversal.

As duas áreas estão localizadas nos municípios de Cedro e Carnaubeira da Penha, cerca de 563,0 e 501,0 km do Recife (PE), respectivamente. Foram selecionados 20 poços da bacia de Cedro e 12 poços da bacia de Carnaubeira da Penha (Figuras 2 e 3), totalizando 32 poços que serviram como pontos para realizar o nivelamento.

Figura 1 - Bacias Interiores do estado de Pernambuco com destaque para as bacias sedimentares estudadas: Cedro e Carnaubeira

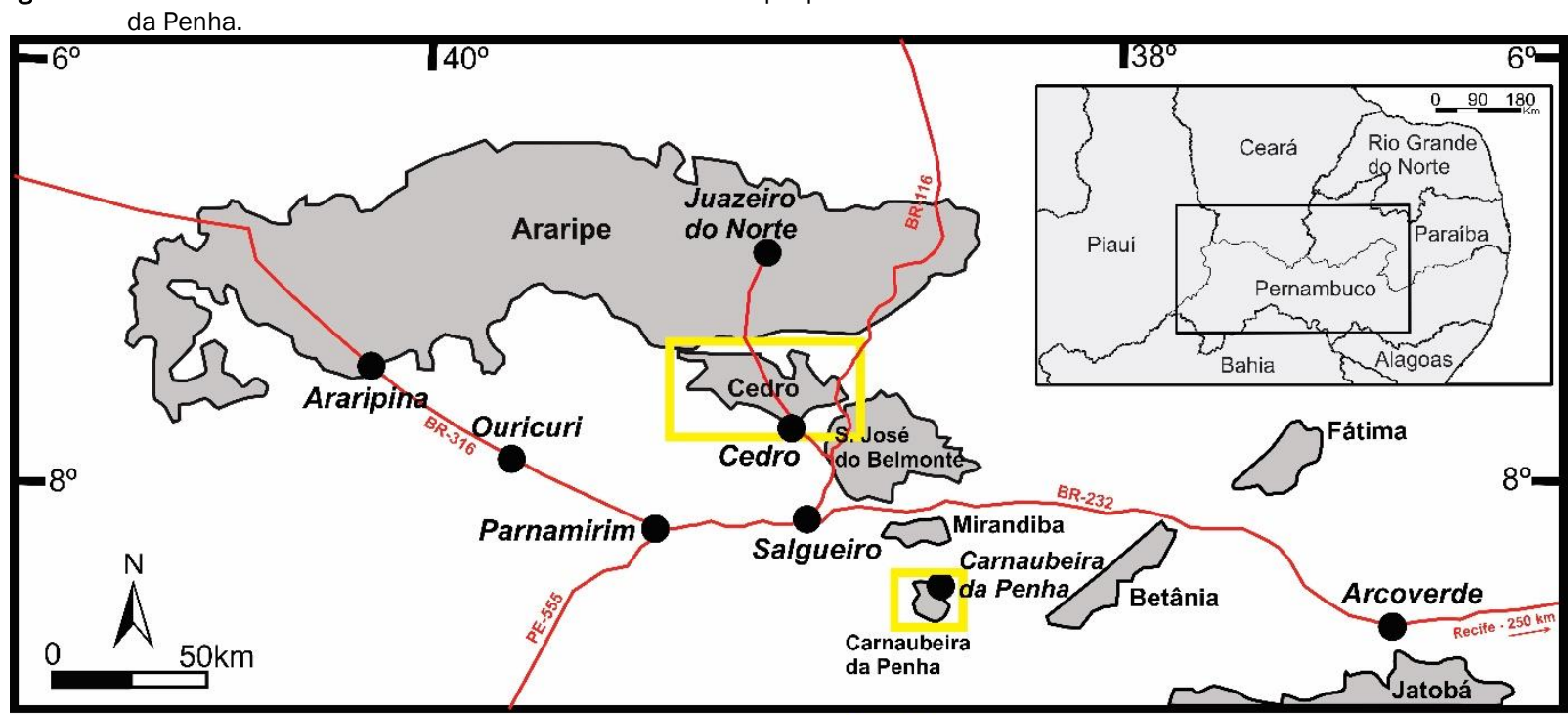

Legenda - Rodovias

Bacias Sedimentares Bacias Estudadas

Municipios

Fonte: Modificado de Hessel et al. (2006). 
Figura 2 - Distribuição dos poços na Bacia de Cedro

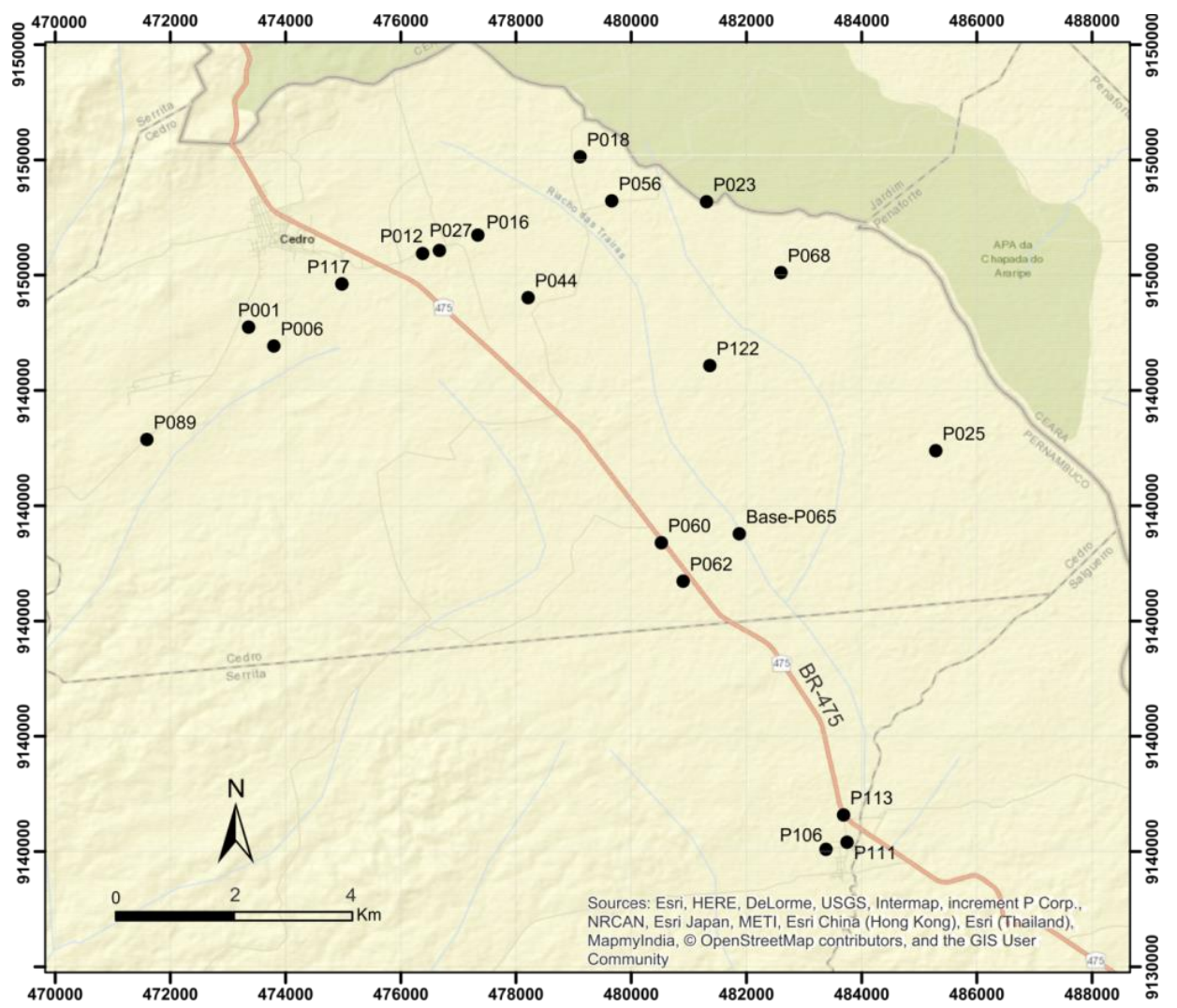

Figura 3 - Distribuição dos poços na Bacia de Carnaubeira da Penha

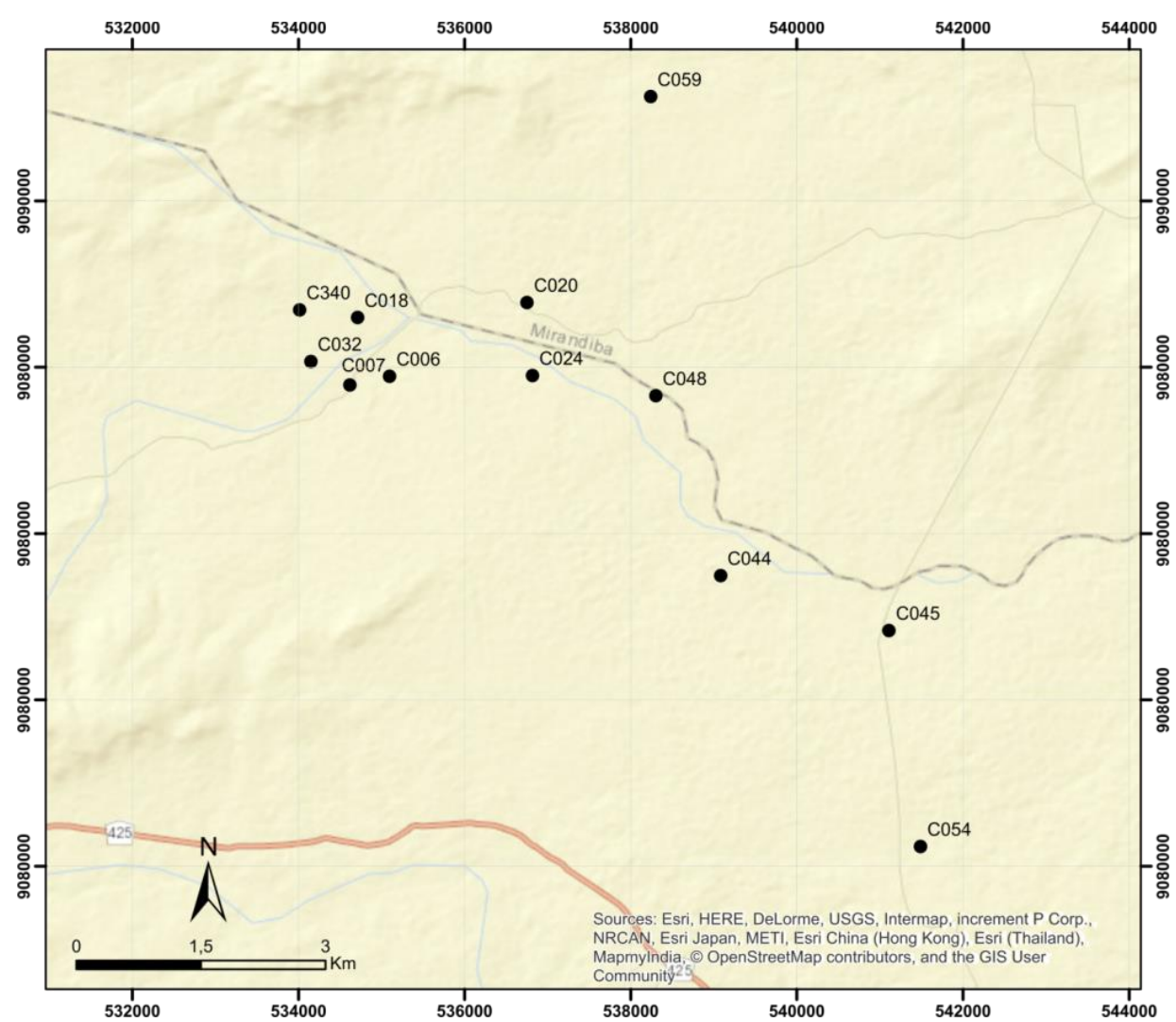




\section{MATERIAL E MÉTODOS}

Para realizar o nivelamento dos poços foram utilizados dois receptores GNSS (Sistemas Globais de Satélite de Navegação) L1 PROMARK 3 MAGELLAN, para tanto, é necessário que uma das antenas (um receptor) permaneça fixa em uma base que possua coordenadas e cotas conhecidas. No Brasil, existe uma rede de estações que serve como referência para esses levantamentos, denominada Rede Brasileira de Monitoramento Contínuo (RBMC), esses dados encontram-se disponíveis diariamente em forma de relatórios no site <www.ibge.gov.br>. A RBMC é um conjunto de estações geodésicas, pertencentes ao Instituto Brasileiro de Geografia e Estatística (IBGE), com receptores GNSS que fornecem relatórios diários contendo informações necessárias para realização dos levantamentos topográficos. A RBMC é hoje a estrutura geodésica de referência mais precisa do país, cujas informações atendem tanto a comunidade científica quanto a prática, e dessa forma, a crescente utilização das técnicas de posicionamento baseadas nos GNSS, o seu papel torna-se cada vez mais relevante (COSTA et al., 2008). Estando a estação base localizada nas proximidades da região de interesse, há uma forte correlação entre os erros calculados na estação base e os erros da estação móvel (MONICO, 2000). Segundo este autor, o DGPS funciona a partir de um receptor estacionário (uma estação da RBMC) rastreando todos os satélites possíveis. Os erros calculados na posição da estação base são semelhantes aos erros da estação móvel, quando essas duas estações estão próximas. No presente trabalho, a RBMC mais próxima é a base do Crato (Identificação: CRAT) que está localizada a cerca de 58,0 km do município de Cedro. Para o município de Carnaubeira da Penha a estação mais próxima é
Afogados da Ingazeira (Identificação: PEAF) que está a cerca de $142,0 \mathrm{~km}$ do município. Como é interessante que a base fique próxima ao conjunto de pontos a ser nivelados, foram selecionados dois pontos (poços) para servirem de base auxiliar, um em cada bacia sedimentar. A quantidade de bases depende do equipamento utilizado e os pontos auxiliares são utilizados para a mudança de base. É um processo comum nesses tipos de levantamentos, pois, transferindo a base para a proximidade do local de trabalho diminui o tempo necessário para o processamento. Para determinar a cota e as coordenadas dessas bases, foi montado um receptor em cada ponto coletando informações na mesma frequência das estações RBMC durante nove horas. Os dados dos receptores e das estações da RBMC foram processados no programa GNSS Solutions para obtenção das coordenadas das bases auxiliares, as quais serviram de base fixa para o levantamento topográfico dos demais pontos.

Vale ressaltar que a altitude determinada utilizando um receptor GNSS não está relacionada ao nível do mar, mas a um elipsoide de referência. 0 modelo geoidal é caracterizado por uma superfície equipotencial do campo de gravidade da Terra, que coincide com o nível médio dos mares. Para estimar o geoide é estabelecido um elipsoide de referência com características matemáticas definidas. A partir disso é possível estimar a superfície geoidal prolongada através dos continentes. Portanto, torna-se necessário conhecer a diferença entre as superfícies geoidal e elipsoidal para que a altitude acima do nível médio do mar possa ser obtida, ou seja, a altitude ortométrica (Figura 4).

Figura 4 - Relação entre altitude geométrica e ortométrica.

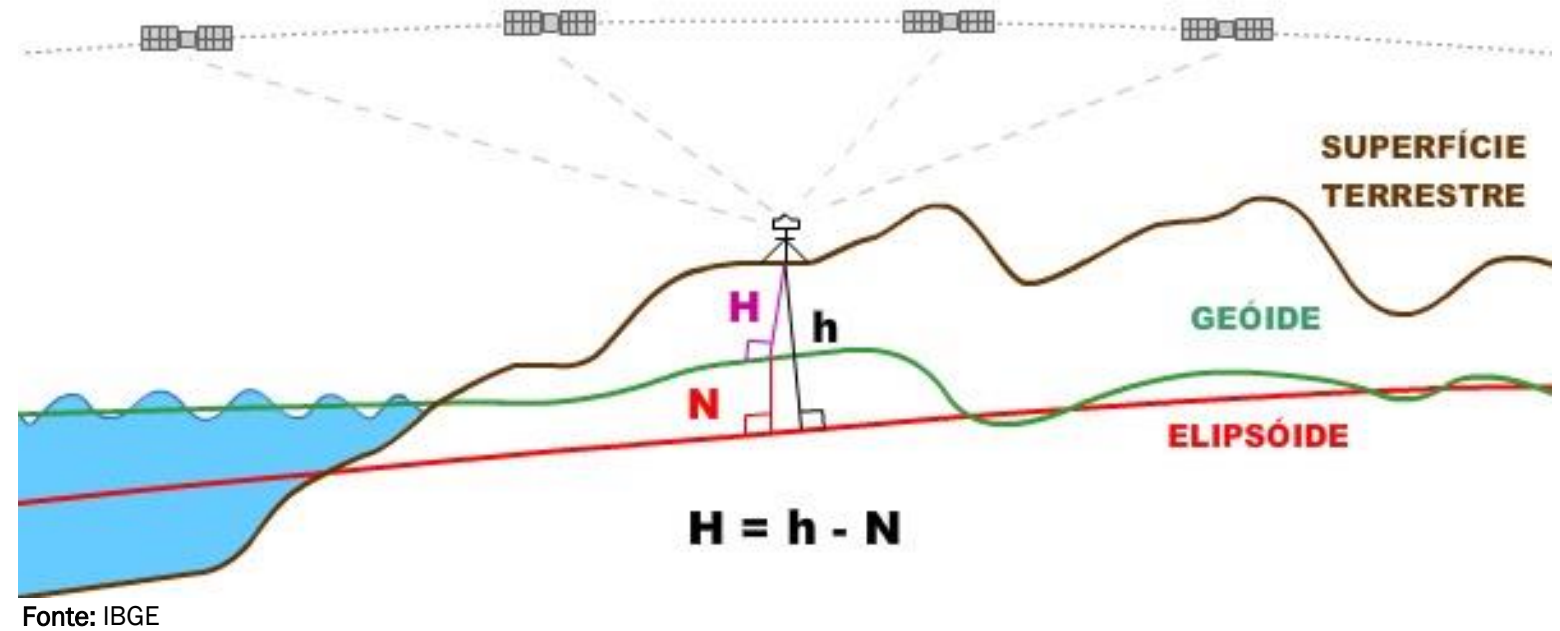

No Brasil, o IBGE, através da Coordenação de Geodésia (CGED) e Escola Politécnica da Universidade de São Paulo (EPUSP) criou o sistema MAPGEO2015, que nos permite obter a ondulação geoidal em um ponto ou conjunto de pontos, desde que as coordenadas estejam em SIRGAS2000 e as latitudes estejam entre $6^{\circ} \mathrm{N}$ e $35^{\circ} \mathrm{S}$ e as longitudes entre $75^{\circ} \mathrm{W}$ e $30^{\circ} \mathrm{W}$, abrangendo o território brasileiro.

Para converter a altitude elipsoidal (h), obtida através de re ceptores GNSS, em altitude ortométrica $(\mathrm{H})$, é necessário utilizar o valor da altura geoidal (N) fornecida pelo MAPGEO, ou outro modelo de ondulação geoidal, utilizando a expressão:

$$
\mathrm{H}=\mathrm{h}-\mathrm{N}
$$

Assim, como para transferência de base, todos os pontos registrados foram processados no software GNSS Solutions com Sistema de Referência Espacial SIRGAS 2000/UTM zona 24S. Após o processamento e obtenção da altura do elipsoide, a 
correção para a altura ortométrica foi feita a partir do modelo geoidal brasileiro MAPGE02015. As imagens do PE3D foram fornecidas como raster no formato TIFF, importadas no software ArcMap e extraídos os valores da altitude.

\section{RESULTADOS E DISCUSSÕES}

Após o processamento dos dados do DGPS foi obtido o valor 9,81 m de correção do elipsoide (altura geoidal) para os pontos de Cedro e -9,49 m para os pontos de Carnaubeira da Penha. Esses valores foram obtidos tomando como referência as bases auxiliares, porém como a distância entre os pontos é pequena, as variações no geoide também são pequenas, nesse caso, a maior variação da altura geoidal de um determinado ponto para a base foi de $4 \mathrm{~mm}$, dessa forma foi utilizado o valor da base para corrigir os demais pontos. 0 resultado encontra-se demonstrado na Tabela 1.

As cotas retiradas das imagens do PE3D estão apresentadas na Tabela 2, juntamente com a comparação com as cotas ortométricas obtidas pelo DGPS.

Tabela 1 - Resultado do nivelamento por DGPS. A nomenclatura Bce refere-se aos poços de Cedro, enquanto a nomenclatura Bcp refere-se aos poços de Carnaubeira da Penha

\begin{tabular}{|c|c|c|c|c|c|c|}
\hline Poço & Zona & UTM Este(m) & UTM Norte(m) & $\begin{array}{l}\text { Elipsoide } \\
\text { (m) }\end{array}$ & $\begin{array}{l}\text { Ondulação } \\
\text { (m) }\end{array}$ & $\begin{array}{c}\text { Cota } \\
\text { ortométrica } \\
(\mathrm{m})\end{array}$ \\
\hline Bce001 & $24 M$ & 473356,381 & 9145099,240 & 532,363 & $-9,810$ & 542,173 \\
\hline Bce006 & $24 M$ & 473797,016 & 9144772,134 & 532,212 & $-9,810$ & 542,022 \\
\hline Bce012 & $24 M$ & 476376,897 & 9146375,765 & 521,370 & $-9,810$ & 531,180 \\
\hline Bce016 & $24 M$ & 477338,049 & 9146695,785 & 501,063 & $-9,810$ & 510,873 \\
\hline Bce018 & $24 M$ & 479113,810 & 9148056,257 & 508,445 & $-9,810$ & 518,255 \\
\hline Bce023 & $24 M$ & 481307,122 & 9147273,597 & 519,733 & $-9,810$ & 529,543 \\
\hline Bce025 & $24 M$ & 485286,515 & 9142953,756 & 491,097 & $-9,810$ & 500,907 \\
\hline Bce027 & $24 M$ & 476671,224 & 9146431,158 & 522,085 & $-9,810$ & 531,895 \\
\hline Bce044 & $24 M$ & 478209,480 & 9145611,009 & 503,284 & $-9,810$ & 513,094 \\
\hline Bce056 & $24 M$ & 479663,601 & 9147291,987 & 512,175 & $-9,810$ & 521,985 \\
\hline Bce060 & $24 M$ & 480523,076 & 9141355,912 & 492,766 & $-9,810$ & 502,576 \\
\hline Bce062 & $24 M$ & 480899,896 & 9140688,702 & 492,620 & $-9,810$ & 502,430 \\
\hline Bce065* & $24 M$ & 481875,609 & 9141511,163 & 480,646 & $-9,810$ & 490,456 \\
\hline Bce068 & $24 M$ & 482599,520 & 9146045,709 & 495,550 & $-9,810$ & 505,360 \\
\hline Bce089 & $24 M$ & 471590,936 & 9143149,766 & 527,765 & $-9,810$ & 537,575 \\
\hline Bce106 & $24 M$ & 483380,567 & 9136035,186 & 477,341 & $-9,810$ & 487,151 \\
\hline Bce111 & $24 M$ & 483746,828 & 9136158,926 & 468,405 & $-9,810$ & 478,215 \\
\hline Bce113 & $24 M$ & 483686,307 & 9136633,681 & 473,517 & $-9,810$ & 483,327 \\
\hline Bce117 & $24 M$ & 474976,904 & 9145847,192 & 509,146 & $-9,810$ & 518,956 \\
\hline Bce122 & $24 M$ & 481363,463 & 9144433,257 & 494,432 & $-9,810$ & 504,242 \\
\hline Bсp006 & $24 \mathrm{~L}$ & 535096,662 & 9083891,590 & 426,792 & $-9,490$ & 436,282 \\
\hline Вср007 & $24 \mathrm{~L}$ & 534618,596 & 9083785,874 & 429,531 & $-9,490$ & 439,021 \\
\hline Вср018 & $24 \mathrm{~L}$ & 534712,486 & 9084597,410 & 449,361 & $-9,490$ & 458,851 \\
\hline Вср020** & $24 \mathrm{~L}$ & 536752,104 & 9084778,482 & 441,588 & $-9,490$ & 451,078 \\
\hline Вср024 & $24 \mathrm{~L}$ & 536818,546 & 9083900,680 & 424,925 & $-9,490$ & 434,415 \\
\hline Вср032 & $24 \mathrm{~L}$ & 534148,739 & 9084069,599 & 444,926 & $-9,490$ & 454,416 \\
\hline Вср034 & $24 \mathrm{~L}$ & 534014,710 & 9084689,305 & 451,743 & $-9,490$ & 461,233 \\
\hline Вср044 & $24 \mathrm{~L}$ & 539082,962 & 9081494,359 & 432,977 & $-9,490$ & 442,467 \\
\hline Вср045 & $24 \mathrm{~L}$ & 541110,233 & 9080834,497 & 403,646 & $-9,490$ & 413,136 \\
\hline Вср048 & $24 \mathrm{~L}$ & 538302,988 & 9083657,151 & 410,481 & $-9,490$ & 419,971 \\
\hline Вср054 & $24 \mathrm{~L}$ & 541488,462 & 9078236,698 & 412,203 & $-9,490$ & 421,693 \\
\hline Вср059 & $24 \mathrm{~L}$ & 538240,763 & 9087254,018 & 445,569 & $-9,490$ & 455,059 \\
\hline
\end{tabular}

$\left({ }^{\star}\right)$ = Ponto que serviu como base auxiliar para Cedro; $\left({ }^{* *}\right)$ = Ponto que serviu como base auxiliar para Carnaubeira da Penha. 
Tabela 2 - Comparação entre as cotas ortométricas (DGPS) e as cotas obtidas pelo projeto PE3D

\begin{tabular}{|c|c|c|c|c|c|}
\hline \multirow[b]{2}{*}{ Poço } & \multicolumn{2}{|c|}{ Coordenadas Geodésicas(m) } & \multirow{2}{*}{$\begin{array}{l}\text { Cota } \\
\text { Ortométrica } \\
\text { - DGPS }(\mathrm{m})\end{array}$} & \multirow{2}{*}{$\begin{array}{l}\text { Cota } \\
\text { PE3D } \\
(\mathrm{m})\end{array}$} & \multirow{2}{*}{$\begin{array}{c}\text { Diferença } \\
\text { entre cotas } \\
(\mathrm{m})\end{array}$} \\
\hline & UTM(E) & UTM(N) & & & \\
\hline Bce001 & 473356,381 & 9145099,240 & 542,173 & 541,934 & $-0,239$ \\
\hline Bce006 & 473797,016 & 9144772,134 & 542,022 & 541,598 & $-0,424$ \\
\hline Bce012 & 476376,897 & 9146375,765 & 531,180 & 531,266 & 0,086 \\
\hline Bce016 & 477338,049 & 9146695,785 & 510,873 & 510,746 & $-0,127$ \\
\hline Bce018 & 479113,810 & 9148056,257 & 518,255 & 518,082 & $-0,173$ \\
\hline Bce023 & 481307,122 & 9147273,597 & 529,543 & 529,702 & 0,159 \\
\hline Bce025 & 485286,515 & 9142953,756 & 500,907 & 501,485 & 0,578 \\
\hline Bce027 & 476671,224 & 9146431,158 & 531,895 & 531,644 & $-0,251$ \\
\hline Bce044 & 478209,480 & 9145611,009 & 513,094 & 512,469 & $-0,625$ \\
\hline Bce056 & 479663,601 & 9147291,987 & 521,985 & 521,795 & $-0,190$ \\
\hline Bce060 & 480523,076 & 9141355,912 & 502,576 & 502,859 & 0,283 \\
\hline Bce062 & 480899,896 & 9140688,702 & 502,430 & 502,711 & 0,281 \\
\hline Bce065 & 481875,609 & 9141511,163 & 490,456 & 490,438 & $-0,018$ \\
\hline Bce068 & 482599,520 & 9146045,709 & 505,360 & 505,297 & $-0,063$ \\
\hline Bce089 & 471590,936 & 9143149,766 & 537,575 & 537,615 & 0,040 \\
\hline Bce106 & 483380,567 & 9136035,186 & 487,151 & 487,071 & $-0,080$ \\
\hline Bce111 & 483746,828 & 9136158,926 & 478,215 & 477,900 & $-0,315$ \\
\hline Bce113 & 483686,307 & 9136633,681 & 483,327 & 483,071 & $-0,256$ \\
\hline Bce117 & 474976,904 & 9145847,192 & 518,956 & 519,003 & 0,047 \\
\hline Bce122 & 481363,463 & 9144433,257 & 504,242 & 504,456 & 0,214 \\
\hline Вср006 & 535096,662 & 9083891,590 & 436,282 & 436,242 & $-0,040$ \\
\hline Вср007 & 534618,596 & 9083785,874 & 439,021 & 438,969 & $-0,052$ \\
\hline Вср018 & 534712,486 & 9084597,410 & 458,851 & 458,433 & $-0,418$ \\
\hline Вср020 & 536752,104 & 9084778,482 & 451,078 & 451,155 & 0,077 \\
\hline Вср024 & 536818,546 & 9083900,680 & 434,415 & 434,422 & 0,007 \\
\hline Вср032 & 534148,739 & 9084069,599 & 454,416 & 454,052 & $-0,364$ \\
\hline Вср034 & 534014,710 & 9084689,305 & 461,233 & 461,004 & $-0,229$ \\
\hline Вср044 & 539082,962 & 9081494,359 & 442,467 & 441,988 & $-0,479$ \\
\hline Вср045 & 541110,233 & 9080834,497 & 413,136 & 413,167 & 0,031 \\
\hline Вср048 & 538302,988 & 9083657,151 & 419,971 & 419,737 & $-0,234$ \\
\hline Вср054 & 541488,462 & 9078236,698 & 421,693 & 421,348 & $-0,345$ \\
\hline Вср059 & 538240,763 & 9087254,018 & 455,059 & 455,018 & $-0,041$ \\
\hline
\end{tabular}

Nota-se que as cotas obtidas pelos dois processos são semeIhantes, havendo pouca diferença entre elas, o que não representaria alterações importantes da carga hidráulica, consequentemente os mapas potenciométricos resultantes dos dois nivelamentos seriam idênticos. Sendo a carga hidráulica (h) a diferença entre a cota do terreno $(Z)$ e a profundidade da água no poço (NE), temos $h=Z$ - NE. Os valores que podem influenciar na carga hidráulica são, portanto, o Z e o NE. O nível de precisão dos valores de $\mathrm{h}$ depende da escala de trabalho $\mathrm{e}$ morfologia do terrenos. Mapas potenciométricos em escalas regionais, como 1:250.000, com terrenos ondulados, podem ser aceitas imprecisões na carga hidráulica de até 2,5m. Em estudos localizados, os erros na obtenção das cargas hidráulicas devem ser inferiores a $10 \mathrm{~cm}$. 0 estudo estatístico mostrou que a maior diferença, em termos absolutos, foi 0,625 m, enquanto a menor diferença foi $0,007 \mathrm{~m}$, a média 0,211 m, com desvio padrão 0,167 m. A figura 5 mostra a relação entre as cotas ortométrcas do DGPS e as cotas do PE3D. Percebese uma convergência entre as altitudes, cujo coeficiente de correlação linear é 0,99996. Vale salientar que o ângulo das duas retas de ajuste aproxima-se de 45 graus implicando em uma boa semelhança entre os valores duas variáveis, ou seja, o valor de uma corresponde a praticamente ao mesmo valor da outra. A distribuição das variações entre as cotas do DGPS e as cotas do PE3D pode ser visualizada na Figura 6. 0 histograma desta figura mostra claramente uma distribuição assimétrica dos dados, com concentração do lado esquerdo, ou seja, dos valores menores, sendo $78,0 \%$ dos erros inferiores a $0,31 \mathrm{~m}$. 
Figura 5 - Relação entre as cotas ortométricas DGPS e as cotas do PE3D para a Bacia de Cedro e para a Bacia de Carnaubeira da Penha

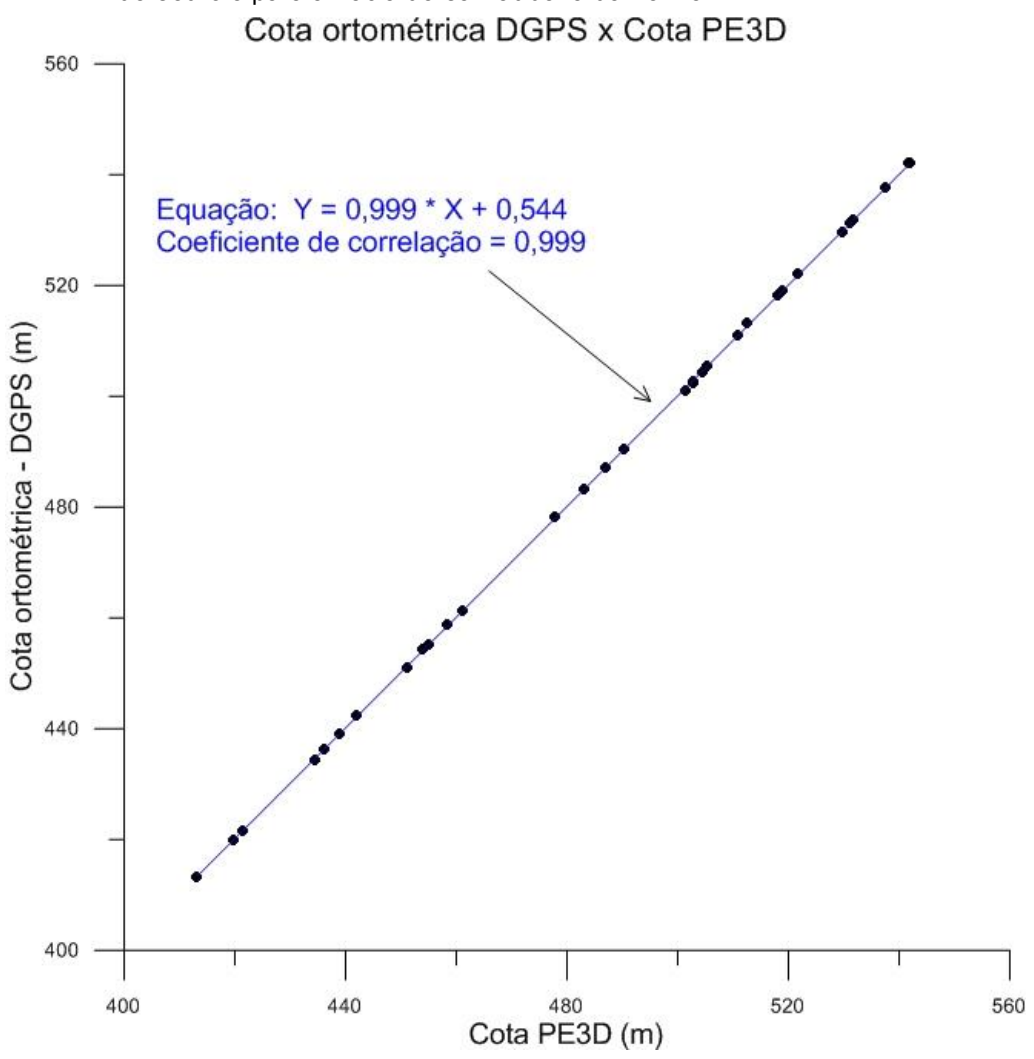

Figura 6 - Distribuição estatística das diferenças de cotas entre DGPS e PE3D (em metros) para as bacias Distribuição das variações entre as cotas DGPS e PE3D para as duas bacias

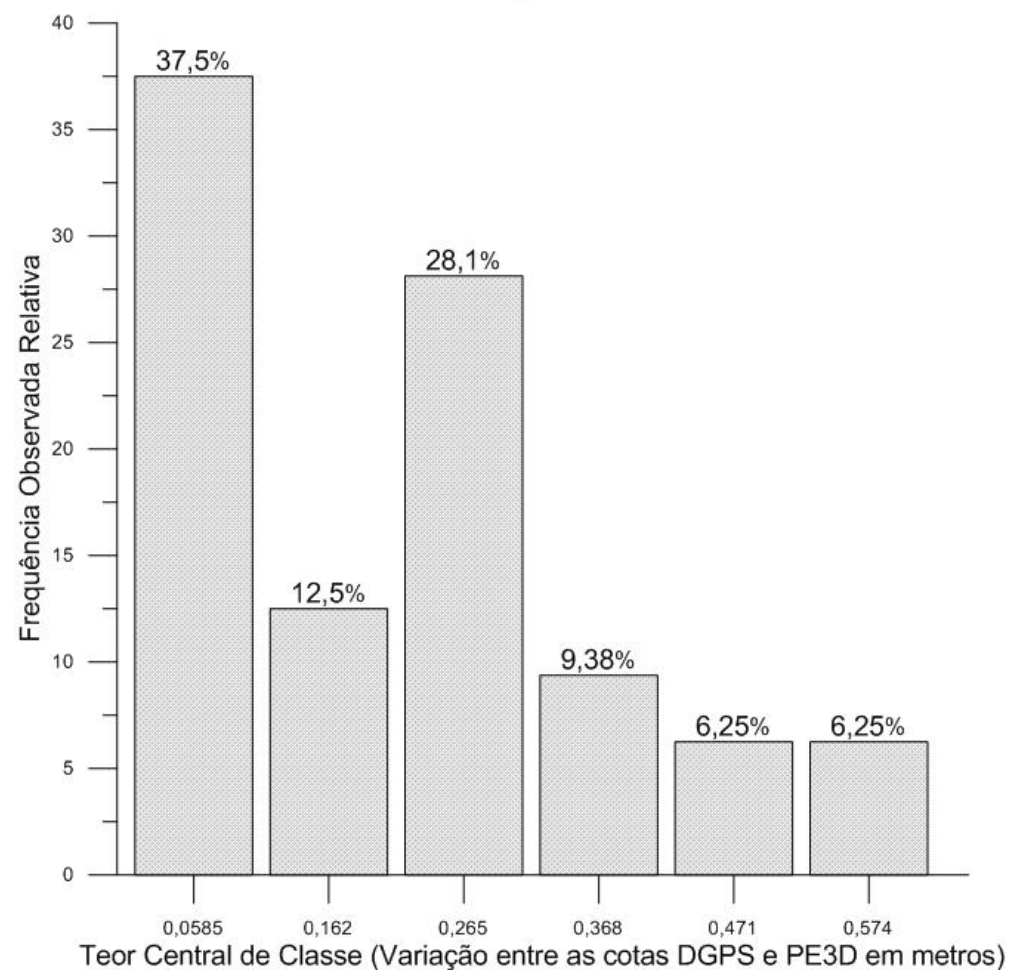

Vale salientar que as coordenadas obtidas com um GPS de navegação, utilizado para o cadastramento de poços, não são tão precisas quanto às obtidas pelo DGPS, dessa forma, utilizar as coordenadas do GPS para obtenção das cotas nas ima gens do PE3D, a princípio poderia resultar em erros acima do aceitável. Entretanto, durante o estudo também foram obtidas as coordenadas por meio do GPS de navegação Garmin $60 C S x$, e os valores foram comparados na tabela 3. 
Tabela 3 - Coordenadas dos poços obtidas com GPS de navegação e DGPS

\begin{tabular}{|c|c|c|c|c|c|}
\hline \multirow{2}{*}{ Poço } & \multicolumn{2}{|c|}{ Coordenadas Garmin (m) } & \multicolumn{2}{|c|}{ Coordenadas DGPS(m) } & \multirow{2}{*}{$\begin{array}{c}\text { Erro } \\
\text { posição } \\
(\mathrm{m})\end{array}$} \\
\hline & UTM(E) & UTM(N) & UTM(E) & UTM(N) & \\
\hline Bce001 & 473355,584 & 9145099,853 & 473356,381 & 9145099,240 & 1,005 \\
\hline Bce006 & 473795,076 & 9144771,240 & 473797,016 & 9144772,134 & 2,136 \\
\hline Bce012 & 476376,565 & 9146375,765 & 476376,897 & 9146375,765 & 0,332 \\
\hline Bce016 & 477338,301 & 9146694,834 & 477338,049 & 9146695,785 & 0,984 \\
\hline Bce018 & 479114,109 & 9148055,107 & 479113,810 & 9148056,257 & 1,188 \\
\hline Bce023 & 481308,752 & 9147272,735 & 481307,122 & 9147273,597 & 1,844 \\
\hline Bce025 & 485286,743 & 9142953,664 & 485286,515 & 9142953,756 & 0,246 \\
\hline Bce027 & 476672,358 & 9146431,430 & 476671,224 & 9146431,158 & 1,166 \\
\hline Bce044 & 478210,478 & 9145609,787 & 478209,480 & 9145611,009 & 1,578 \\
\hline Bce056 & 479661,614 & 9147292,364 & 479663,601 & 9147291,987 & 2,022 \\
\hline Bce060 & 480523,869 & 9141354,376 & 480523,076 & 9141355,912 & 1,729 \\
\hline Bce062 & 480899,736 & 9140686,665 & 480899,896 & 9140688,702 & 2,043 \\
\hline Bce065 & 481876,326 & 9141509,620 & 481875,609 & 9141511,163 & 1,701 \\
\hline Bce068 & 482601,490 & 9146043,555 & 482599,520 & 9146045,709 & 2,919 \\
\hline Bce089 & 471590,270 & 9143149,577 & 471590,936 & 9143149,766 & 0,692 \\
\hline Bce106 & 483380,817 & 9136032,010 & 483380,567 & 9136035,186 & 3,186 \\
\hline Bce111 & 483745,798 & 9136157,744 & 483746,828 & 9136158,926 & 1,568 \\
\hline Bce113 & 483685,658 & 9136632,591 & 483686,307 & 9136633,681 & 1,269 \\
\hline Bce117 & 474975,044 & 9145846,541 & 474976,904 & 9145847,192 & 1,971 \\
\hline Bce122 & 481363,702 & 9144431,189 & 481363,463 & 9144433,257 & 2,082 \\
\hline Вср006 & 535096,568 & 9083892,371 & 535096,662 & 9083891,590 & 0,787 \\
\hline Вср007 & 534618,342 & 9083785,529 & 534618,596 & 9083785,874 & 0,428 \\
\hline Вср018 & 534711,455 & 9084597,097 & 534712,486 & 9084597,410 & 1,077 \\
\hline Вср020 & 536749,726 & 9084775,235 & 536752,104 & 9084778,482 & 4,025 \\
\hline Вср024 & 536816,992 & 9083899,743 & 536818,546 & 9083900,680 & 1,815 \\
\hline Вср032 & 534148,004 & 9084071,179 & 534148,739 & 9084069,599 & 1,743 \\
\hline Вср034 & 534013,915 & 9084689,847 & 534014,710 & 9084689,305 & 0,962 \\
\hline Вср044 & 539082,427 & 9081491,705 & 539082,962 & 9081494,359 & 2,707 \\
\hline Вср045 & 541109,313 & 9080829,863 & 541110,233 & 9080834,497 & 4,724 \\
\hline Вср048 & 538302,489 & 9083655,812 & 538302,988 & 9083657,151 & 1,429 \\
\hline Вср054 & 541486,222 & 9078235,634 & 541488,462 & 9078236,698 & 2,480 \\
\hline Вср059 & 538240,496 & 9087252,344 & 538240,763 & 9087254,018 & 1,695 \\
\hline
\end{tabular}

Na coluna “Erro posição”, estão registradas as distâncias entre o ponto com coordenada obtida pelo GPS de navegação e o ponto com coordenada obtida pelo DGPS. A maior diferença entre as coordenadas obtidas pelos dois métodos foi de 4,724 $\mathrm{m}$, enquanto que a menor diferença foi de 0,246 m. A média foi de $1,780 \mathrm{~m}$ e o desvio padrão de 0,995 m. As diferenças aqui registradas não são suficientes para que a cota obtida utilizando as coordenadas do GPS de navegação apresentem erros que possam mudar a forma do mapa potenciométrico. Com isso, fica demostrando que as coordenadas obtidas com GPS de navegação, possuem o mesmo grau de precisão para a determinação das cotas com o PE3 que as coordenadas obtidas com DGPS.

\section{CONCLUSÃO}

As elevações obtidas a partir das imagens do PE3D, compara das as determinadas por DGPS, apresentam uma boa aproximação, com pequenas variações, e permitem a elaboração de mapas potenciométricos detalhados, uma vez que essas diferenças alteram pouco ou quase nada nas curvas equipotenciais. Dessa forma, a utilização de mapas potenciométricos feitos a partir de imagens do projeto PE3D é recomendada tanto para estudos regionais e preliminares, quanto para estudos detalhados. Também foi demonstrando que, mesmo obtendo-se as coordenadas dos poços com o GPS de navegação, é possível obter as cotas pelo PE3D sem grandes diferenças em relação ao DGPS.

\section{REFERÊNCIAS}

COSTA, S. M. A.; LIMA, M. A. D. A.; JÚNIOR, N. J. D. M.; ABREU, M. A.; SILVA, A. L. D.; FORTES, L. P. S. RBMC em tempo real, via NTRIP, e seus benefícios nos levantamentos RTK e DGPS. 
In: SIMPÓSIO BRASILEIRO DE CIÊNCIAS GEODÉSICAS E TECNOLOGIAS DA GEOINFORMAÇÃO, 2. [Anais...] 8-11 set. 2008, Recife. As Ciências geodésicas e tecnologias da geoinformação no contexto de estudos e aplicações em geociências, engenharias e meio ambiente. Recife: Universidade Federal de Pernambuco, 2008.

DEMETRIO, J. G.; CORREIA, L.C. \& SARAIVA, A.L. Utilização de imagens, 2006.

SRTM na confecção de mapas potenciométricos. XIV CONG. BRAS. DE ÁGUAS SUBTERRÂNEAS, 14., 2006. [Anais...]. ABAS. Curitiba, 2006.

HESSEL, M. H.; TOMÉ, M.E.; MOURA, C.R. Ostracodes mesozoicos das bacias do interior do Nordeste Brasileiro: o estado da arte. Revista de Geologia, v. 19, n. 2, p. 187-206, 2006.
IBGE (Instituto Brasileiro de Geografia e Estatística), Modelo de Ondulação Geoidal. Disponível em: https://ww2.ibge.gov.br/home/geociencias/geodesia/modelo geoidal.shtm. Acesso: 18 fev. 2019.

LÖBLER, C. A.; TERRA, L. G.; SILVÉRIO DA SILVA, J. L. Dados da CPRM/SIAGAS e Imagens STRM como Base Cartográfica na Elaboração de Mapeamento em Recursos Hídricos Subterrâneos em Escala Municipal: o Caso de Nova Palma, RS. Revista Brasileira de Geografia Física, v. 7, n. 3, p. 513-523, 2014.

MONICO, J. F. G. Posicionamento pelo NAVSTAR-GPS: descrição, fundamentos e aplicações. São Paulo: Editora UNESP, 2000. 